\title{
Cuestiones críticas sobre educación matemática y educación indígena en Colombia'
}

\author{
Critical issues in mathematics education and \\ indigenous education in Colombia
}

Questões críticas em educação matemática
e educação indígena na Colômbia

Recibido: mayo de 2013

Aceptado: agosto de 2013

Aldo Iván Parra Sánchez ${ }^{2}$

Jorge Isidro Orjuela Bernal ${ }^{3}$

\section{Resumen}

El presente artículo retoma algunas de las problemáticas planteadas en la producción etnomatemática internacional sobre educación indígena, ejemplificándolas en el contexto del pueblo indígena nasa en Colombia, con la doble intención de a) relatar parte del proceso educativo adelantado por el pueblo nasa en Tierradentro y b) aportar a la discusión académica propuesta que a nuestro juicio merece ser ampliada a partir a las experiencias colombianas.

Palabras clave: Alumno. Diversidad. Cultura-Religión. Etnomatemáticas. Educación indígena. Educación matemática critica.

\section{Abstract}

This article takes up some of the issues raised in the international ethnomathematics production indigenous education in the context ejemplificándolas Nasa indigenous people in Colombia, with the dual purpose of a) tell part of the educational process in advance by the Nasa people in Tierradentro b) contribute to academic discussion proposal that we believe deserves to be expanded from the Colombian experience.

Keywords: Student. Diversity. Culture-Religion. Ethnomathematics. Indigenous education. Critical mathematics education.

\section{Resumo}

El este artigo tem algumas das questões levantadas na produção etnomatemática educação indígena internacional no contexto ejemplificándolas Nasa povos indígenas na Colômbia, com o duplo objectivo de a) contar uma parte do processo educativo com antecedência pelo povo NASA em Tierradentro b) contribuir para a proposta de discussão acadêmica que acreditamos que merece ser ampliado a partir da experiência colombiana.

Palavras-chave: aluno. Diversidade. Cultura-Religião. Etnomatemática. Educação indígena. Educação matemática crítica.

1 Artículo de Investigación.

2 Centro de Investigaciones Indígenas de Tierradentro (CIIT), Colombia. Contacto: aiparras@unal.edu.co,

3 Institución Educativa Agroforestal Yuç Kwet Zuun. Colombia. Contacto: aiparras@unal.edu.co 


\section{Introducción}

Cuando los estudios en etnomatemática consiguen superar una emotiva explosión inicial, generada por el reconocimiento de la presencia de saberes relacionables con matemáticas al interior de comunidades indígenas, (usualmente marcados con un hálito de exotismo y benevolencia paternalista), y consiguen profundizar su mirada al punto de ser sensibles a las consecuencias que generan los mismos estudios en las poblaciones, aparecen nuevos desafíos, que involucran la ruptura de paradigmas colonialistas de investigación, así como un replanteamiento de los objetivos que se pretende alcanzar con las aplicaciones escolares de la etnomatemática. El presente texto dará cuenta de algunos de estos desafíos, evidentes en la experiencia de trabajo de una comunidad indígena nasa en Tierradentro, a la cual hemos podido acompañar.

\section{Contextualización Histórica Del Pueblo Nasa}

El pueblo Nasa es actualmente el segundo pueblo indígena colombiano más numeroso, y se localiza principalmente en el departamento del Cauca. Sus contactos con el estado nación datan del siglo XVI, cuando Sebastián de Belálcazar intentó conquistar por la fuerza sus territorios. A pesar de ser derrotado consiguió "fundar" algunas poblaciones cerca de lugares sagrados para los Nasa, en lo que hoy se conoce como la región de Tierradentro. Estos episodios dieron el inicio a una larga relación de lucha y negociación entre este pueblo y los distintos estamentos enviados para diluirlos en el estado (soldados, sacerdotes, comerciantes, profesores,...). Para 1971 los Nasa y 6 pueblos más deciden conformar una organización política colectiva llamada Consejo Regional Indígena Del Cauca (CRIC), con el fin de estructurar un proyecto de resistencia y autonomía, que involucrara diferentes ámbitos del desarrollo y no únicamente las demandas políticas.

Contextualización Resguardo de San Andrés. Uno de los resguardos indígenas más representativos de la región de Tierradentro es el de San Andrés de Pisimbalá. Allí no solo fue instalada desde hace 300 años una capilla doctrinera, sino que hace poco más de 30 años fue descubierta una serie de hipogeos con vestigios arqueológicos de una cultura prehispánica que aún no se puede determinar con exactitud. Esta situación trajo una especial atención sobre la región, creándose un parque arqueológico y ampliando la presencia de población campesina que había llegado desde 1940, fruto de la violencia política. Esto, a su vez, demandó la creación de una escuela con primaria y bachillerato. Actualmente dentro del resguardo hay una infraestructura turística montada alrededor del parque, manejada principalmente por los colonos no indígenas.

El colegio de San Andrés reflejaba fielmente las premisas con las que se había manejado la educación para pueblos indígenas en toda Colombia (y por eso creemos que vale la pena contar esta historia): se aplicaba el modelo misionero de sumisión colonial, ampliamente documentado por Cauty (2001) y po López (2009), que básicamente pretende que los indígenas aprendan a comportarse en un papel subalterno dentro del gran estado. Para el caso de las matemáticas los objetivos se definen claramente: dominar las operaciones aritméticas básicas por medio de la memorización de sus algoritmos. Es decir, una matemática de bajo nivel, mecanicista y sin sentido. Los contenidos de la secundaria se tornan una suerte de catecismo, lleno de oraciones (fórmulas) que no se comprenden y que remiten a un mundo inexistente. Si ya de por sí ese tipo de educación es catalogado como inconveniente para la población en general, para el caso indígena llega a ser nociva y represora en grado mayor, toda vez que invisibiliza toda la racionalidad y saber que proviene de la cultura.

A pesar que desde 1970 se venían ensayando experiencias piloto en resguardos cercanos para atender el hecho cultural, y que a partir de 1991 la educación en pueblos indígenas quedó desligada de la iglesia católica, los cambios en la enseñanza aprendizaje de las matemáticas fueron mínimos, bajo el inveterado supuesto de la universalidad de la matemática. En el colegio central los docentes no eran indígenas y tenían una actitud abiertamente hostil a las tradiciones indígenas (en medio de un resguardo indígena!) y lo máximo que se alcanzó fue a abrir una materia de baja intensidad horaria para aprender los rudimentos de la 
escritura en la lengua, y en ella se presentaban los nombres de ciertos números. Después de varios años de reflexión político-educativa por parte de líderes comunitarios, se logra dar un paso importante frente a estas reflexiones. El cabildo indígena decide en abril de 2010 tomar el control de la escuela, estructurando un nuevo proyecto. De este modo, emprenden la que se llamó minga educativa, la cual busca construir pensamiento para defender el territorio, fortalecer la cultura, ser autónomos y pervivir. Sin lugar a dudas, esta educación plantea nuevos desafíos frente a la enseñanza en la escuela. Esta propuesta lleva desarrollándose por 3 años y es nuestro interés analizar estas dinámicas desde los marcos explicativos disponibles en educación matemática a partir del acompañamiento activo que se ha realizado.

\section{Marcos Conceptuales}

Se pretende tener como referente los desarrollos conceptuales que el movimiento indígena caucano ha planteado desde 1978 a través de su Programa de Educación Bilingüe Intercultural (PEBI). Dicho programa tiene como finalidad implementar propuestas curriculares, formar docentes y producir materiales, y estructurar la dimensión educativa del proceso político-organizativo de resistencia emprendido por los pueblos indígenas del Cauca. En las propuestas del programa prevalecen la comunitariedad, la cosmovisión y la interculturalidad. De este modo, se busca fortalecer los conocimientos culturales -mediante el uso de las formas ancestrales de comunicación-, afirmar y desarrollar las relaciones sociales y políticas en la comunidad.

Tal como se comenta en Rapppaport (2008a), y en sus documentos propios (PEBI 2004), el PEBI concibe la educación más allá de la escuela, dado que es vista como un proceso de producción de pensamiento que permite analizar los problemas e las comunidades y fortalecer su identidad cultural por medio de su redescubrimiento y dinamización.
Con ello busca formar dirigentes con una posición crítica y en armonía con el plan de vida. Es así como aparecen los Proyectos Educativos Comunitarios (PEC), como eje fundamental de integración de toda la comunidad a partir del plan de vida, de sus costumbres y prácticas culturales. Es importante tener en cuenta que el PEC no es un elemento que se constituye una vez y deja de modificarse, sino que, al contrario, está en constante proceso de construcción. Además, no funciona como en las instituciones oficiales donde los directivos diseñan y formulan la manera en cómo se llevara a cabo la educación, sino que con el PEC es la comunidad -por medio de su participación en diferentes espacios como mingas y asambleas-, quien provee todos los elementos, físicos y conceptúales para su continua construcción.

La minga educativa de San Andrés de Pisimbalá, a través de su PEC, busca aumentar la capacidad comunitaria para administrar, orientar, dirigir, organizar y construir los procesos y propuestas educativos con un posicionamiento crítico, dialógico, investigativo, creativo y propositivo, conformando con ello una educación genuinamente propia. Dicha educación potencia tanto los espacios escolarizados como los no escolarizados, fortalece la familia y la comunidad y se rige bajo principios como el cuidado y defensa de Uma Kiwe (madre tierra), la identidad cultural, la construcción colectiva del conocimiento, el uso y valoración del Nasayuwe como lengua originaria, entre otros. La propuesta educativa de este resguardo posee como referente de construcción curricular las jigras ${ }^{4}$ del conocimiento, es decir, no se habla de materias o de áreas obligatorias sino de jigras.

La primera jigra es Uma kiwete nesyuka ki'sna que tiene como propósito reconocer a la madre tierra como principio de vida, donde todos los que comparten el territorio tienen la responsabilidad social, espiritual y cultural de generar espacios de armonía y equilibrio para posibilitar un buen vivir. La segunda jigra es Çxhaba üusa's nuycxhäcxhaka $^{6}$, desde donde se invita a tener la identidad

4 Dentro del contexto nasa, jigra se le denomina a la mochila (bolso tejido en lana o cabuya) en la que de acuerdo a los sabedores de la comunidad se lleva lo necesario para vivir.

5 Permanezcamos para siempre en nuestra madre tierra, practicando la ritualidad.

6 Fortalezcamos el corazón de la identidad del pueblo. 
de un pueblo, una cultura y mantener un espíritu colectivo. La tercera jigra es Jadacxah umn fxizen ${ }^{7}$, encargada de visibilizar el conocimiento propio referente a los tejidos y formas particulares de comunicación, de asumir los otros conocimientos que sean necesarios para avanzar en el plan de vida; es en esta jigra donde se "incluyen" las matemáticas y se generan desafíos frente a su enseñanza-aprendizaje. Por último la cuarta jigra es el Eçx eçx fxi'zn ${ }^{8}$ , donde se asumen los procesos de educación para que el cuerpo individual siembre el espíritu de la colectividad para defender los intereses comunitarios; la preocupación aquí no es únicamente por el cuerpo individual, sino que incluye las prácticas culturales, el territorio y el plan de vida.

Como puede verse, esta nueva organización educativa plantea para los saberes matemáticos, fines y métodos diferentes a los que se plantearían desde las directrices nacionales. Y esto nos lleva a indagar dentro de la educación matemática, y dentro de la etnomatemática, por un marco compatible con la organización educativa de los Nasa, encontrando insuficientes los planteamientos recogidos por Blanco (2008), ya que esta propuesta no puede ser reducida a la etnoeducación, asumida por este autor como una "solución educativa" ofrecida por el gobierno central para grupos o comunidades étnicas. Ya que esta propuesta no es para los indígenas, sino de los indígenas, nacida desde sus propias pretensiones; tampoco es una solución, sino un proceso de diálogo en situación de tensión.

Vemos con insatisfacción que desarrollos en etnoeducación e interculturalidad, como los planteados por Parra (2003), Aroca (2007) o Santillán (2007), a pesar de adherir a posturas bienintencionadas sobre una educación que debería "estar ligada al ambiente, al proceso productivo, al proceso social y cultural, con el debido respeto de sus creencias y tradiciones" (Ministerio de Educación Nacional, 2004: 7), usualmente se reducen a la búsqueda de técnicas eficaces para mejorar la enseñanza de contenidos definidos por el gobierno central, manteniendo sin problematizar el espacio del aula de clase, y las relaciones de poder y saber que impone la arquitectura de una escuela. Por eso preferimos acudir a las tendencias con enfoque crítico.

En este estudio recogemos, desde el campo de la etnomatemática, las contribuciones de Bernardi \& Caldeira (2012) sobre la escuela indígena y los de Knijnik (1996) sobre el carácter político de los trabajos en etnomatemática. Desde el campo de la educación matemática crítica, consideramos los aportes de Skovsmose acerca del porvenir de los estudiantes en situación de frontera. De este modo se problematizan aspectos tales como la diversidad de la sociedad, la falta de igualdad, de justicia social, de autonomía de estudiantes y profesores, etc.

\section{Metodología}

Para abordar la situación descrita estamos acudiendo a nuestras interacciones con la comunidad educativa de San Andrés de Pisimbalá, que comienzan en 2006 y se mantienen hasta la fecha en el marco de una investigación indígena sobre matemáticas en todo Tierradentro, así como la vinculación desde 2012 de uno de los autores al colegio como docente, lo que le permite conocer de primera mano las tensiones y decisiones presentes al interior del proyecto educativo. Esto posibilitó realizar entrevistas con los actores del proceso, y en cierto sentido, ser también uno de ellos, por lo que podría decirse que nuestra observación es participante, sin embargo preferimos la noción de acompañamiento o de trabajo colaborativo planteada por Rappaport (2008a), siendo por medio de dicho acompañamiento que se generan una serie de inquietudes alrededor de la educación matemática y la educación indígena en Colombia. En el trabajo colaborativo, el investigador externo se suma al desarrollo de los proyectos y tareas definidos internamente por las comunidades, adaptándose a nuevas instancias de validación.

\footnotetext{
7 Tejiendo vida entre todos.

8 Permanecer con dinamismo y alegría en el territorio.
} 


\section{Análisis}

Como resultado y aporte del presente artículo, basados en el marco conceptual y la permanencia en el territorio, conseguimos formular una serie de cuestionamientos, que sirven para plasmar las tensiones observadas. Estos son:

¿Qué elementos brinda la escuela indígena para que el paso que se genera de comunidad a sociedad no altere las dinámicas cosmogónicas y de identidad de sus integrantes?

¿Bajo qué elementos la escuela indígena prepara a su comunidad para afrontar temas globalizantes que tienen que ver con la producción de bienes y servicios y la racionalidad depredadora que allí se encuentra inmersa?

¿Cuál es la realidad que viven los sujetos que son egresados de la escuela indígena y como ésta provee herramientas para la continuidad de los planes de vida del sujeto a nivel individual y comunitario?

Por nuestra parte, y situándonos en un país como Colombia, que se encuentra en conflicto armado, en condiciones de abuso y explotación de la niñez podemos también preguntar ¿Qué estrategias brinda la escuela indígena para que los niños y jóvenes se mantengan al margen de la guerra y se provean de lo necesario sin ser abusados y explotados?

\section{Conclusiones}

Nos parece importante señalar que en Colombia los contactos entre pueblos indígenas y lo que se conoce como cultura occidental son bastante antiguos, y también que las iniciativas educativas exteriores no pueden hacer cosa distinta a comprender y sumarse a lo se ha venido desarrollando internamente desde hace 30 años.

Como podemos ver con el caso del pueblo Nasa, estamos frente a una aporía, en el sentido de
Skovsmose, y frente a ello no podemos eludir las responsabilidades que ella demanda para nuestras acciones, y por tanto de la importancia que trae en sí el mismo hecho de plantear con la mayor claridad posible los retos a encarar para propuestas educativas surgidas de los mismos indígenas. Es esencial asumir aquí que no hay respuestas definitivas, y que el trabajo del investigador no necesariamente consiste en dar soluciones, sino también en afinar las preguntas.

\section{Referencias}

Aroca, A. (2007). Una propuesta de enseñanza de geometría desde una perspectiva cultural. Comunidad indígena Ika. Sierra Nevada de Santa Marta. Trabajo de investigación de maestría, Universidad del Valle, Instituto de Educación y Pedagogía, Cali.

Bernardi, L. S.; Caldeira, A. D. (2012). Educação Matemática na Escola Indígena sob uma Abordagem Crítica. Bolema 26(42 B). pp. 409-431.

Blanco, H. (2008). La integración de la etnomatemática en la etnoeducación. Memorias del IX Encuentro Colombiano de Matemática Educativa.

Cauty, A. (2001) ¿Cómo Seguir Siendo Amerindio y Aprender Las Matemáticas que Necesitará? In: ZAPATA, G. (Ed.). Pluriculturalidad y Aprendizaje de La Matemática en América Latina. Madrid: Ed. Morata, p. 49-87.

Knijnik, G. (1996). Exclusão e Resistência: educação matemática e legitimidade cultural. Porto Alegre: Artes Médicas.

López, L. E. (2010). Reaching the unreached: Indigenous intercultural bilingual education in Latin America. "Paper commissioned for the EFA Global Monitoring Report 2010, Reachingthemarginalized. 2009. 
Parra, A. (2003). Acercamiento a la Etnomatemática. Trabajo de Grado, Universidad Nacional de Colombia, Departamento de Matemáticas y Estadística. Bogotá.

Programa de Educacion Bilingue Intercultural (PEBI). (2004). ¿Qué Pasaría Si La Escuela...? Treinta años de construcción de una educación propia. Popayán: Consejo Regional Indígena del Cauca.

Rappaport, J. (2008a). Utopías interculturales. Intelectuales públicos, experimentos con la cultura y pluralismo étnico en Colombia. Bogotá: Editorial Universidad del Rosário, p. 138-175
Rappaport, J. (2008b). Beyond Participant Observation: Collaborative Ethnography as Theoretical Innovation. Collaborative Anthropologies, Washington, v. 1, p.1-31.

Santillán, A; Zachman, P. (2009) Una experiencia de capacitación en Etnomatemática. Revista Latinoamericana de Etnomatemática. 2(1) . P. 27-42. http://www.revista.etnomatematica.org/ index.php/RLE/article/view/14/14Anexo 2. Material didáctico diseñado por los estudiantes del grado décimo e implementación de la estrategia metodológica en preescolar. 